\title{
Synthesis of Bioplastic-based Renewable Cellulose Acetate from Teak Wood (Tectona grandis) Biowaste Using Glycerol-Chitosan Plasticizer
}

\section{BAITI ROHMAWATI ${ }^{*}$, FATIN ATIKAH NATA SYA'IDAH ${ }^{1}$, RHISMAYANTI², DANTE ALIGHIRI ${ }^{1}$ and WILLY TIRZA EDEN ${ }^{1}$}

\author{
${ }^{1}$ Chemistry Department, Faculty of Mathematics and Natural Sciences, Universitas Negeri Semarang, \\ Indonesia. \\ 2Biology Department, Faculty of Mathematics and Natural Sciences, Universitas Negeri Semarang, \\ Indonesia. \\ *Corresponding author E-mail: baitirohmawati6@ gmail.com
}

http://dx.doi.org/10.13005/ojc/3404014

(Received: July 07, 2018; Accepted: July 31, 2018)

\begin{abstract}
Cellulose acetate was synthesized from cellulose which was isolated from teak wood (Tectona grandis) biowaste. The isolation process used an isolation method using nitric acid, sodium hydroxide, sodium sulfite and bleaching with calcium hypochlorite. Cellulose acetate was synthesized with acetic anhydride, toluene as a solvent, and sulphuric acid as a catalyst. Cellulose acetate reacted with acetic acid as a catalyst and glycerol-chitosan as a plasticizer. This product yielded a bioplastic. The synthesized products were characterized by using FTIR and SEM. The bioplastic's mechanical properties were evaluated by ASTM D638 method. Based on the results of FTIR analysis, this result was successfully performed. This condition was shown by the sharpness of the hydroxyl group of cellulose acetate than the hydroxyl group in the cellulose and wood powder. The optimum result of bioplastic was obtained by composition of cellulose acetate: acetic acid: chitosan: glycerol is $0.8 \mathrm{~g}: 15 \mathrm{~mL}: 0,4 \mathrm{~g}: 1 \mathrm{~mL}$.
\end{abstract}

Keyword: Bioplastic, Tectona grandis, Cellulose acetate, Glycerol, Chitosan, Plasticizer.

\section{INTRODUCTION}

Biodegradable polymers expand the range of waste management alternative over conventional plastics, and this is supported by the Life Cycle Assessment ${ }^{1}$. In recent years, the production of biodegradable materials from renewable natural resources (such plants) has got increasing attention, especially in EU countries ${ }^{2}$ and the use of renewable resources has been revitalized ${ }^{3-5}$. If properly managed, this would reduce their environmental impact upon disposal ${ }^{2}$ and, also, it would be technically and economically practicable ${ }^{6}$.

This is an Open Access article licensed under a Creative Commons Attribution-Non Commercial-Share Alike 4.0 International License (https://creativecommons.org/licenses/by-nc-sa/4.0/), which permits unrestricted Non Commercial use, distribution and reproduction in any medium, provided the original work is properly cited. 
Plastics are considered to be the most widely used polymers in our daily life especially in packaging applications. The annual production of petroleum-based plastics exceeded 300 million tons in $2015^{7}$. In fact, 34 million tons of plastic wastes are generated each year throughout the world, and 93\% of them are disposed of in landfills and oceans ${ }^{8}$. To save fossil fuels, reduce $\mathrm{CO}$ emission and plastic wastes, there is found a bioplastic. Bioplastics can be defined as plastics made of biomass such as corn, sugarcane, and wood.

Bioplastics are derived from agricultural resources and biomass feedstock that are renewable and therefore comply with materials that are eco-effcient and sustainable ${ }^{9,10}$. It has been reported that the worldwide production capacity of bioplastics will increase from $0.36 \mathrm{Mt}$ in 2007 to $3.45 \mathrm{Mt}$ in 2020 . Among the biopolymer matrices being utilized for the production of bioplastics, cellulose is considered to be used as the raw material ${ }^{11}$.

Cellulose is the major constituent of all plant materials ${ }^{12}$. Cellulose can be found in the teak wood (Tectona grandis) sawdust. In general, the composition of wood is $50 \%(\mathrm{w} / \mathrm{w})$ cellulose, $15-30 \%(w / w)$ hemicellulose, $15-35 \%(w / w)$ lignin, and $5-30 \%(\mathrm{w} / \mathrm{w}) \mathrm{ash}^{13}$.

To improve the quality of bioplastics, cellulose is acetylated to be a cellulose acetate. Cellulose acetate is typically made from wood pulp through reaction with acetic acid and acetic anhydride in the presence of sulfuric acid to form cellulose triacetate ${ }^{14-16}$. Cellulose acetate presents a high glass transition temperature and cannot be melt-processed as a raw material because of its thermal properties. For this reason, plasticizers are usually added to cellulose acetate. These substances allow the melting of the polymers without thermal degradation and reduce the rigidity 17,18

Biodegradable plastics, based on cellulose acetate, were studied and the produced plastic decomposed in soil or water within a few years. However, the material can be recycled, also, or burned without residue 1 . There were studies of the important properties of cellulose acetate including mechanical strength, impact resistance, transparency, colorability, fabricating versatility, moldability, and di-electric strength ${ }^{19,20}$. Natural plastic is produced in a fluid form and, therefore, it is shaped easily and does not require a large amount of energy. This is compared with the conventional plastic which is usually stored as granules and needs a massive amount of energy so that it can be shaped by mo lding, injection, or extrusion ${ }^{21}$.

Based on this explanation, this research aims to find out the most effective and efficient method to utilize cellulose from cellulose biowaste of teak wood become a bioplastic and to analyze the characteristics of produced bioplastic. Wood waste in this research supplied by the furniture industry in Jepara which had been thrown away and burned away.

\section{EXPERIMENTAL}

\section{Materials}

Teak wood in the experiments was supplied by the furniture industry in Jepara District, Central Java Province, Indonesia. Teak wood was washed to remove its impurities. Chitosan in the experiment was purchased in CV Chimultiguna with $98 \%$ purity. The reagents and chemicals using in our study were such as hexane, ethanol, $\mathrm{NaOH}, \mathrm{HNO}_{3}, \mathrm{H}_{2} \mathrm{SO}_{4}$, $\mathrm{NaOCl}, \mathrm{Na}_{2} \mathrm{SO}_{3}$, glycerol, acetic acid, water, and compost. The chemicals were purchased from Merck.

\section{Pretreatment of raw material}

The sawdust was washed several times with water and then dried at $60^{\circ} \mathrm{C}$ for 24 hours. $300 \mathrm{~g}$ of the dried powder was extracted with a hexane and ethanol mixture with ratio 2: 1 and refluxed for $6 \mathrm{~h}$ then allowed to cool and filtered. Then, the residue was hydrolyzed using sulfuric acid p.a. $2.2 \%$ with a temperature of $121^{\circ} \mathrm{C}^{22}$.

\section{Cellulose isolation use the multistage pulping method}

The processed sawdust was mixed with $400 \mathrm{~mL}$ of $3.5 \%$ nitric acid. The mixture was immersed in a water bath for $2 \mathrm{~h}$ at $90^{\circ} \mathrm{C}$. Furthermore, the obtained residue was washed with distilled water. The residue is immersed into $300 \mathrm{~mL}$ of sodium hydroxide and sodium sulfite solution each $2 \%$ $\mathrm{w} / \mathrm{v}$ at $50^{\circ} \mathrm{C}$ for 1 hour. Then, the residue was filtered and washed. The residue was bleached by $200 \mathrm{~mL}$ of water and $3.5 \% \mathrm{w} / \mathrm{v}$ sodium hypochlorite mixture 
(water ratio and 3.5\% sodium hypochlorite solution is 1: 1), then it was boiled for $10 \mathrm{~min}$. filtered and washed. The obtained residue from the filtration was heated at $80^{\circ} \mathrm{C}$ in the $200 \mathrm{~mL}$ of sodium hydroxide $17.5 \mathrm{w} / \mathrm{v}$ for $30 \mathrm{~min}$. then filtered and washed. The obtained residue is cellulose 22 .

The obtained cellulose was dried in the oven at $60^{\circ} \mathrm{C}$ for 1 hour. Pure dry cellulose was stored in a desiccator for bioplastic synthesis.

\section{Cellulose acetate synthesis Cellulose activation}

4 grams of cellulose was refluxed with $100 \mathrm{ml}$ of $3 \mathrm{M}$ acetic acid and $5 \mathrm{ml}$ of concentrated sulfuric acid $98 \%(\mathrm{v} / \mathrm{v})$. Then, it was heated at $40^{\circ} \mathrm{C}$ for 3 hours. The resulted precipitate is separated from the filtrate by filtration, then it was dried in an oven at $60^{\circ} \mathrm{C}$ and weighed until its mass was constant then it was deposited in the exciter.

\section{Cellulose acetylation}

4 gram activated cellulose was refluxed with $10 \mathrm{ml}$ acetic anhydride, $5 \mathrm{ml}$ toluene, and 5 $\mathrm{ml}$ of concentrated sulfuric acid $98 \%(\mathrm{v} / \mathrm{v})$. The mixture was heated at $40^{\circ} \mathrm{C}$ for 8 hours. The product was cooled, and the precipitate was filtered. The remained toluene was evaporated, and the rest of the other reagents were cleaned by wash the precipitate several times with water. The precipitate was dried with an oven at $60^{\circ} \mathrm{C}$ to a constant weight.

Cellulose acetate substitution degree calculation

1) Dried cellulose acetate $0,5 \mathrm{~g}$ was added by $50 \mathrm{~mL}$ of water ( $\mathrm{pH}$ is arranged until 7)

2) $\quad 25 \mathrm{ml} 0.5 \mathrm{~N} \mathrm{NaOH}$ was added and heated while stirring until the precipitate dissolved and homogeneous then the solution was cooled.

3) The mixture was titrated with $0.02 \mathrm{~N} \mathrm{HCl}$ until the $\mathrm{pH}$ returns 7. The $\mathrm{DS}$ value was calculated with the titration formula as follows ${ }^{24}$

$$
\begin{aligned}
& \mathrm{DS}=\frac{162 \times\left(\mathrm{N}_{\mathrm{NaOH}} \times \mathrm{V}_{\mathrm{NaOH}}-\mathrm{N}_{\mathrm{HCl}} \times \mathrm{V}_{\mathrm{HCl}}\right)}{1000 \times \mathrm{W}-\left(\mathrm{M}_{\mathrm{w}}-1\right) \times\left(\mathrm{N}_{\mathrm{NaOH}} \times \mathrm{V}_{\mathrm{NaOH}}-\mathrm{N}_{\mathrm{HCl}} \times \mathrm{V}_{\mathrm{HCl}}\right)} \\
& \text { With: } \\
& \mathrm{W}: \text { : weight of cellulose ester } \\
& \mathrm{MW}: \text { molecular weight of bound substituent at } \\
& \quad \text { cellulose }
\end{aligned}
$$

\section{Bioplastic synthesis}

Dry cellulose acetate was weighed as much as 0.804 grams and added $15 \mathrm{ml}$ of vinegar solution $0.665 \mathrm{M}$. it was added with $0.4 \mathrm{~g}$ of chitosan and $1 \mathrm{~mL}$ of glycerol and stirred for 15 minutes. After the mixture was homogeny, it was shaped by a casting method. In this method, the biopolymer sample was shaped with a glass plate. The mold was flat and then dried with an oven at $60^{\circ} \mathrm{C}$ for 1 hour. The experiment was repeated by varying the volume of glycerol addition.

\section{Bioplastic characterization}

In this study, several tests were performed to study the characteristics of varied bioplastics. The characteristic tests include the analysis of functional group analysis, pore structure analysis, degradation ability of bioplastic, and mechanical properties of bioplastic.

\section{Functional group analysis}

Functional group analysis performed by using FTIR Spectrometer Frontier instrument which can identify functional groups in a material through typical IR uptake. Analysis using FTIR is done in the range $300-4000 \mathrm{~cm}^{-1}$.

\section{Scanning electron microscope (SEM) analysis}

SEM is a method of characterization and research of the pore structure of an object. This SEM analysis can be performed on the teak wood powder surface, cellulose surface, cellulose acetate surface, and bioplastic.

\section{Degradation ability of bioplastic}

Bioplastic degradation tests were performed by burying all three bioplastic samples for 30 days. The percentage loss of mass from bioplastics will be known through this analysis. We can determine percent loss of mass of the three bioplastic samples through the equation

Mass loss (\%) $=\frac{\mathrm{W}_{\mathrm{i}}-\mathrm{W}_{\mathrm{f}}}{\mathrm{W}_{\mathrm{i}}} \times 100 \%$

with:

Wi: bioplastic mass before degradation

Wf: bioplastic mass after degradation

\section{Mechanical properties of bioplastic}

A mechanical test was performed to measure the tensile strength and elongation of the three bioplastic samples. The used method was ASTM D638. 


\section{Data Analysis Technique}

Obtained data from the bioplastic degradation test were analyzed using a t-test $(P<0.05)$. The data were analyzed using the Chisquare test with $\mathrm{P}=0.05$.

\section{RESULT AND DISCUSSION}

\section{Bioplastic's functional group analysis}

FTIR spectra from teak wood powder, pretreatment wood powder, cellulose, and cellulose acetate to know every step of the research.

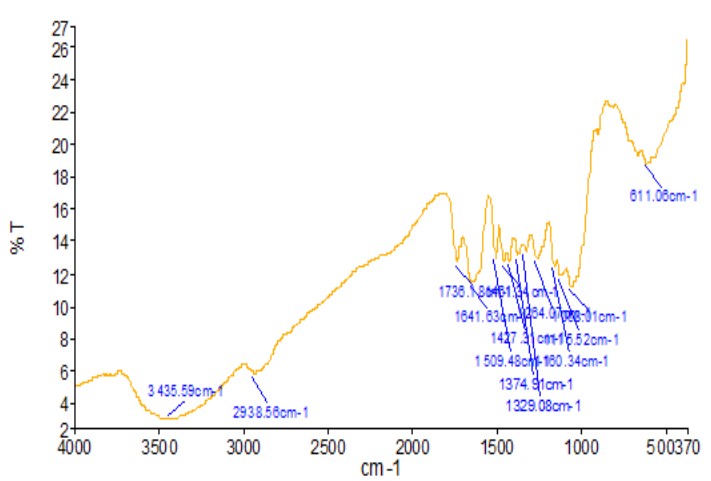

(a)

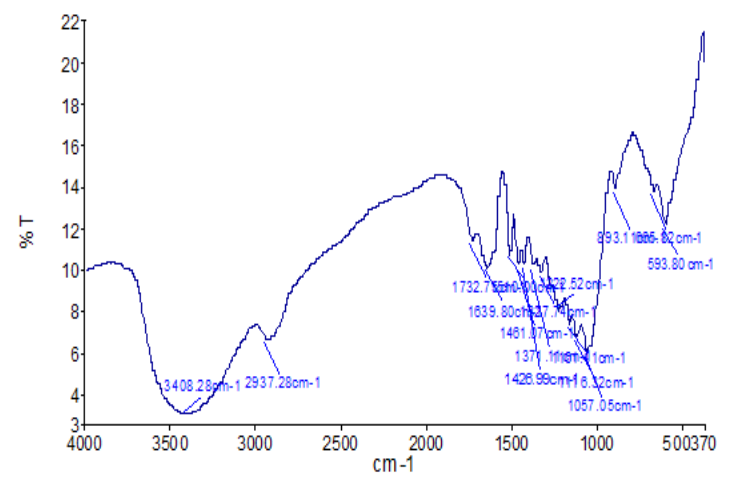

(b)

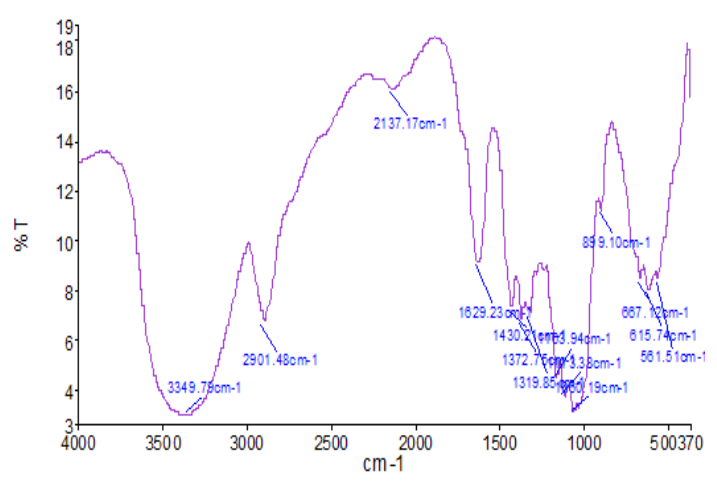

(c)

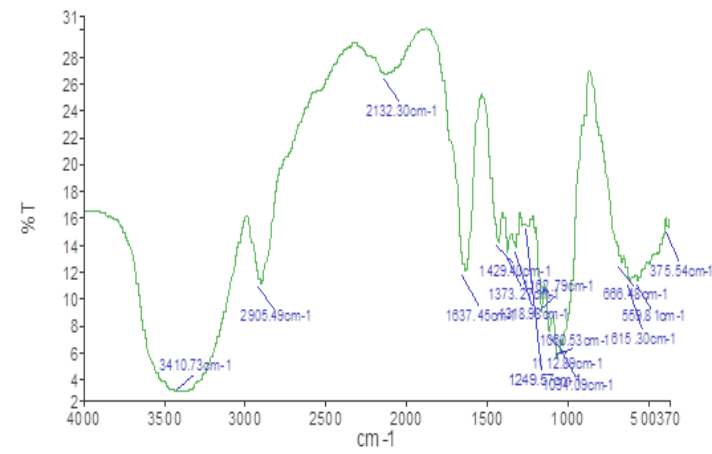

(d)

Fig. 1. FTIR spectra a) Teak wood powder, b) pretreatment wood powder, c) cellulose, d) cellulose acetate

Structure of compound from teak wood powder, pretreatment teak dust, cellulose, and cellulose acetate confirmed using FTIR spectroscopy. This was done to see the success of cellulose isolation process from Tectona grandis teak wood waste. In Fig.1.a, the results show that on raw teak powder, it was probably to have cellulose content, which was proved by the presence of typical cellulose groups, $-\mathrm{OH}$, in absorbent bands at $3435.59 \mathrm{~cm}^{-1}$. In Fig. 1.b, after pretreatment of teakwood dust, cellulose began to appear. It was identified in absorbent bands $3408.28 \mathrm{~cm}^{-1}$, where the valleys were sharper. After being isolated, the absorbent bands in the 3349.78 $\mathrm{cm}^{-1}$ area was increasingly apparent (Fig. 1.c). Most likely the cellulose from teakwood powder had been isolated. This was also supported by the presence of specific groups of cellulose other than the hydroxyl group, such as the methylene group $\left(\mathrm{CH}_{2}\right)$ in the $2901.48 \mathrm{~cm}^{-1}$ absorption band which was a C-H stretch vibration, and the -O-groups that assemble cellulose appeared in the absorption band 1319.85 $\mathrm{cm}^{-1}$ and $1372.75 \mathrm{~cm}^{-1}$.

The FTIR Cellulose acetate spectra were depicted in Fig. 1.d. When compared to the cellulose FTIR spectra, the hydroxyl group on the cellulose was sharper than the hydroxyl group on cellulose acetate. This proved that there was an acetylated hydroxyl group. Not all hydroxyl groups could be acetylated, so the degree of substitution (DS) needs to be calculated. The FTIR cellulose acetate spectra also proved that the acetylation process did not break the main structure of cellulose, still indicating the presence of cellulose-specific groups, such $\mathrm{C}-\mathrm{H}$ in $2905.49 \mathrm{~cm}^{-1}$ absorptions, group -O- in $1318.98 \mathrm{~cm}^{-1}$ and $1373.21 \mathrm{~cm}^{-1}$. 
Scanning electron microscope (SEM) analysis

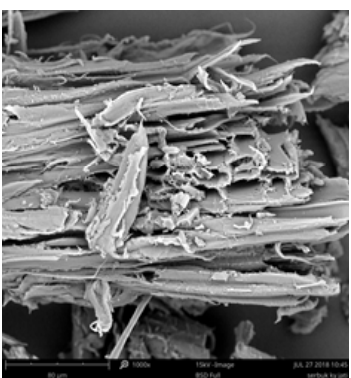

(a)

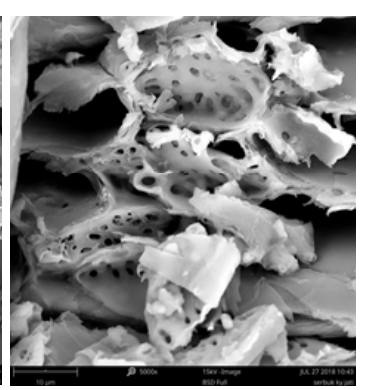

(b)
Fig. 2. SEM micrographs teak wood powder surface structure at magnification (a) $1000 \mathrm{x}$ and (b) 5000x

Figure 2a showed that the surface of teak wood sawdust was elongated in the form of fibrils. This form was the surface form of cellulose. Therefore, from the results of this SEM test, it could be seen that there was cellulose content in teak wood powder.

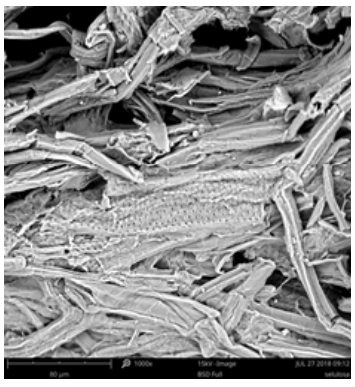

(a)

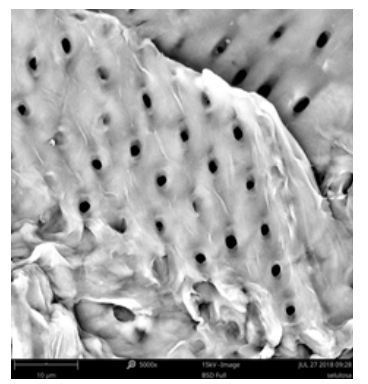

(b)
Fig. 3. SEM micrographs cellulose surface structure at magnification (a) $1000 \mathrm{x}$ and (b) $5000 \mathrm{x}$

In Fig. 3b, it was seen that cellulose structures like twisted ropes tied to each other between hydrogen liners. Fibrils were a collection of cellulosic molecules and contained regular and less regular parts ${ }^{23}$. Fibrils did not have the same diameter, as shown in Fig. 3a showing different fibrils. In the figure also showed that the visible fibrillar bundle consisted of fibrils with various diameters and single molecules directed

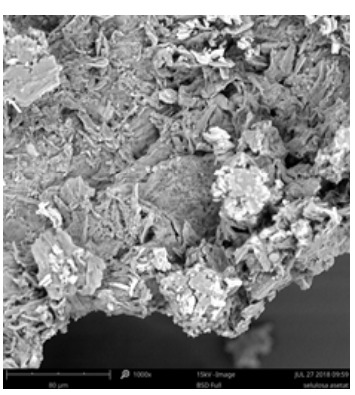

(a)

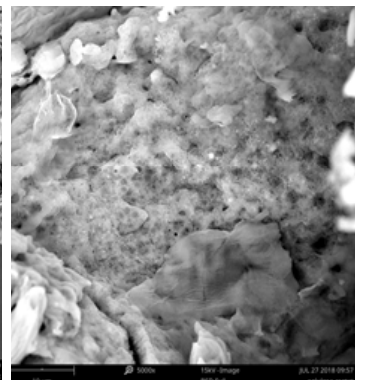

(b)
Fig. 4. SEM micrographs cellulose acetate surface structure at magnification (a) 1000x and (b) 5000x diagonally from one fibril to another. The arrangement of such fibrillation units was similar to the arrangement of cellulose fibrillar in soft cotton ${ }^{23}$.

Figure $4 a$ showed that cellulose acetate fibrils were more regular than fibrils in cellulose (Fig. 3a). It also means that the produced cellulose acetate has a plastic character. The cellulose acetate pores were shown in Fig. 4b. These pores showed a modification of cellulose with acetyl groups.

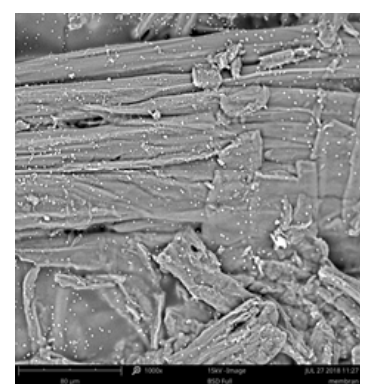

(a)

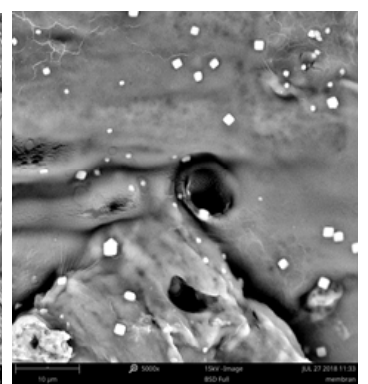

(b)
Fig. 5. SEM micrographs bioplastic surface structure at magnification (a) 1000x and (b) 5000x

Figure $5 \mathrm{a}$ and $5 \mathrm{~b}$ showed that the bioplastic which was composed of cellulose acetate, chitosan and glycerol had a smoother surface when compared to cellulose and cellulose acetate. It occurred because glycerol had covered the surface of the bioplastic. The presence of pores in bioplastics suggested that bioplastics were able to interact with microbes so that it would affect the rate of bioplastic degradation in the soil.

\section{Cellulose acetate degree of substitution (DS) calculation}

The degree of substitution (DS) value shows the average substitution rate of each glucose unit in the polysaccharide. If all of the hydroxyl groups in each unit of glucose is esterified, the DS value is 3. The higher the DS value, the properties of the plastic of the cellulose ester is higher ${ }^{24}$.

During acetylation of free hydroxyl groups at $\mathrm{C}_{2}, \mathrm{C}_{3}$ and $\mathrm{C}_{6}$ atoms in cellulose may be substituted with acetyl groups. Therefore, in theory, the maximum DS value is 3. Substitution occurs because of the addition-elimination mechanism.

Three free hydroxyls $(-\mathrm{OH})$ groups have different reactivity. The $-\mathrm{OH}$ group of $\mathrm{C}_{6}$ atoms is 
more reactive and more rapidly acetylated than $-\mathrm{OH}$ groups in $\mathrm{C}_{2}$ and $\mathrm{C}_{3}$ atoms due to steric hindrances. If the $-\mathrm{OH}$ group of $\mathrm{C}_{2}$ and $\mathrm{C}_{3}$ atoms are compared, then the $-\mathrm{OH}$ group at $\mathrm{C}_{2}$ is more reactive. This is because the $-\mathrm{OH}$ group at $\mathrm{C}_{2}$ is closer to hemiacetal and more acidic than the $-\mathrm{OH}$ group of $\mathrm{C}_{3}$ atoms.

The value of this cellulose acetate DS could be well measured using a titration method on esters whose esterification process ${ }^{24}$. Based on the titration method, cellulose acetate with method 1 had a DS value 1,4.

\section{Bioplastic degradation analysis}

The biodegradation test was carried out by the method buried in soil mix with compost. The addition of compost was useful for accelerating the decay of bioplastic samples. The simplest quantitative method for characterizing the biodegradation of a polymer is to determine the mass loss of the polymer material. In this study, 3 pieces of bioplastic samples were analyzed for their ability of biodegradation. The time required to analyze bioplastic biodegradation capability was 30 days. The observed results of the three mass of bioplastics before and after degradation were based on Table 1,

Bioplastic was reduced by an average mass of $44.12 \%$ after being buried in the soil-compost mixture for 30 days. This proved that bioplastics were easier to degrade than conventional plastics which were non-biodegradable. This bioplastic was easily degraded due to the amorphous form of a polymer so that microorganisms in the soil could attack the bioplastic molecules.

Table 1: Observation Result of Before and After Bioplastic's Mass

\begin{tabular}{lccc}
\hline Bioplastic & $\begin{array}{c}\text { Initial mass } \\
\text { (gram) }\end{array}$ & $\begin{array}{c}\text { Mass after } \\
\text { degradation (gram) }\end{array}$ & $\begin{array}{c}\text { Mass loss } \\
(\%)\end{array}$ \\
\hline Cellulose acetate + Chitosan + Glycerol (1) & 0,340 & 0,149 & 56,17 \\
Cellulose acetate + Chitosan + Glycerol (2) & 0,350 & 0,231 & 34,00 \\
Cellulose acetate + Chitosan + Glycerol (3) & 0,320 & 0,185 & 42,18 \\
\hline
\end{tabular}

\section{Mechanical properties of bioplastic}

A mechanical test was performed to measure the tensile strength and elongation of the three of the bioplastic samples. The method used was ASTM D638. The results of the three bioplastic mechanical tests were shown in Figure 6.

Figure 6 showed that bioplastic with the addition of glycerol would decrease the tensile strength but increase the breaking elongation. The cellulose chain functional group is a hydroxyl group which can interact with the $-\mathrm{O},-\mathrm{N}$, and $-\mathrm{S}$ groups, forming hydrogen bonds where the hydrogen bond is longer than the covalent bond but the bond is weaker. Therefore, in addition to glycerol, there was an interaction between the hydrogen bonds in cellulose and glycerol. Besides, with the addition of glycerol may increase the flexibility of bioplastics and increase molecular mobility so that bioplastics get more elastic and greater breaking elongation.

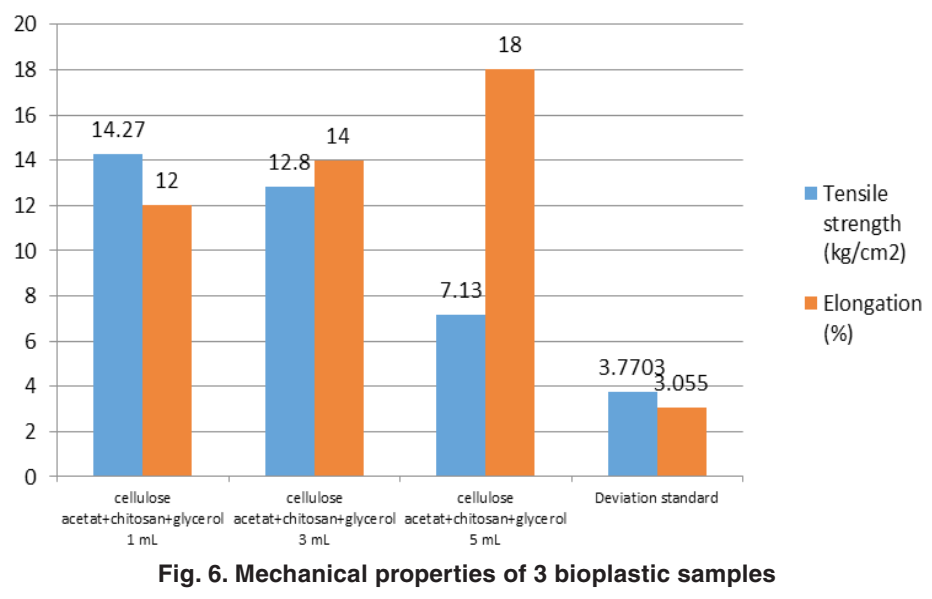




\section{CONCLUSION}

The isolation of cellulose from teak wood by an effective three-step process like pretreatment method with hexane, ethanol, and sulphuric acid. Then, the obtained cellulose was isolated using nitric acid, sodium hydroxide, sodium sulfite and bleaching with calcium hypochlorite. Cellulose acetate was synthesized successfully with the yield of $45.88 \%$ by using acetic anhydride, toluene as a solvent, and sulphuric acid as a catalyst. Cellulose acetate reacted with acetic acid and glycerol became a bioplastic. The synthesized products were characterized by using FT-IR and SEM. The mechanic behavior was evaluated by ASTM D638. Thus, the successful preparation of bioplastic would provide a promising opportunity to select the agricultural residues as a potent and competitive candidate for industrial utilization.

\section{ACKNOWLEDGMENT}

The authors gratefully acknowledge the financial assistance supported by Kementerian Riset, Teknologi, dan Pendidikan Tinggi on Program Kreativitas Mahasiswa (PKM) program.

\section{REFERENCES}

1. Mostafa, N.A.; Farag, A.A.; Abo-dief, H.M. Arabian Journal of Chemistry., 2015, 4, 1-8.

2. Davis, G.; Song, J.H. Ind Crop Prod., 2006, 23, 147-161.

3. Tabone, M.D.; Cregg, J.J.; Beckemn, E.J.; Landis, A.E. Eviron. Sci. Technol., 2010, 44, 8264-8269.

4. Catote, C.A.; Barreiro, M.F.; Rodrigues, A.E. Ind. Crops Prod., 2008, 27, 168-174.

5. Kiatsimkul, P.P.; Suppes, G.J.; Hsieh, F.H.; Lozada, Z.; Tu, Y.C. Ind. Crops Prod., 2008. 27, 257-264.

6. Tanaka, R.; Hirose, S.; Hatakeyama, H. Bioresour. Technol., 2008, 99, 3810-3816.

7. Mekonnen, T.; Mussone, P.; Khalil, H.; Bressler, D. J. Mater. Chem., 2013, 1, 13379.

8. Pathak, S.; Sneha, C.L.R.; Mathew, B.B. J. Polym. Biopolym. Phys. Chem., 2014, 2, 84-90.

9. Khalil, H.P.S.A.; Tehrani, M.A.; Davoudpour, Y. $J$ Reinf Plast Compos., 2013, 32, 330-356.

10. La, M.F.P.; Morreale M. Compos Part A: Appl Sci Manuf., 2011, 42, 579-588.

11. Agustin, M.B.; Ahmad, B.; Alonzo, S.M.M.; Patriana, F.M. Journal of Reinforced Plastics and Composites., 2014, 0, 1-9.

12. Pavithra, R.; Gunasekaran, S.; Sailatha, E.; Kamatchi, S. Journal of Applied Science and Engineering Methodologies., 2016, 2, 246-249.

13. Singh, M. Journal of Applied Polymer
Science., 2004, 92, 3437-3446.

14. Bikales, N. M.; Segal, L. Cellulose, and cellulose derivatives. High polymers Series V. New York: Wiley., 1971

15. Gedon, S.; Fengl, T. Kirk-Othmer Encyclopedia of Chemical Technology. New York: Wiley., 1993, 5, 496-563.

16. Larock, R. C. Comprehensive organic transformations. New York: VCH., 1989, 980-985.

17. Tanaka, S.; Iwata, T.; lji, M. ACS Sustainable Chemistry \& Engineering., 2017, 5, 1485-1493.

18. Phuong, V.T.; Verstiche, S.; Cinelli, P.; Anguillesi, I.; Coltelli, M.B.; Lazzeri, A. Journal of Renewable Materials., 2014, 2, 35-41.

19. Fischer, S.; Thummler, K.; Volkert, B.; Hettrich, K.; Schmidt, I.; Fischer, K. Macromol. Symp., 2008, 1, 89-96.

20. Jinghua, Y.; Doug, D.; Nancy, M.; Ray, J. Pharma. Technol., 2009, 3, 88-100.

21. Xiaoyun, Q.; Shuwen, H. Materials., 2013, 6, 738-781.

22. Ohwoavworhua, F.O.; Adelakun, T.A. Indian Journal of Pharmaceutical Sciences., 2010, 3, 295-301.

23. Fengel, D.; Wegener, G. Gadjah Mada University Press: Yogyakarta., 1995.

24. Xu, Y.; Miladinov, V.; Hanna, M.A. Cereal Chemists., 2004, 81, 735-740. 